\title{
On How to Build a Modern Educational Administration Management Platform in Colleges and Universities under the Credit System
}

\author{
Chengjun Shen \\ Jilin agricultural University, Changchun, China, 130118
}

Keywords: Credit system; Construction; Modernization; Educational administration management

\begin{abstract}
Educational administration management in colleges and universities is an important part of higher education and is the core and foundation of the management in colleges and universities. With the deep and development of the higher education reform, enlargement of size of colleges and universities and the rapid development of computer technology, establishing the modern and scientific educational administration management platform has become the urgent problem in colleges and universities.
\end{abstract}

\section{Introduction}

Educational administration management in colleges and universities is an extremely important part in higher education and is the core and foundation of the school management. With the rapid development of computer and communication technology, higher education puts forward higher request for educational administration work. Changing the traditional management mode and using modern means of scientific management as soon as possible have become a subject to be solved urgently in the whole education system. The article researches the construction and apply of the educational administration management information platform in our school. The traditional educational administration is usually finished by the manual operation. A lot of complicated data, forms and curriculum arrangement are finished by hand, which is both time-consuming and fallible. Along with the advancement of higher education reform, with characters of "course selection system", grade-point system"," flexible educational system"," tutorial system" and "the minor-assistant system" under the credit system, cultivating the personalized and diversified applied talents and creating open, independent selective learning environment have become an inevitable trend of higher education. Higher education puts forward higher request for educational administration work. The traditional teaching management mode can no longer meet the needs of talent cultivation under the new form. With the rapid development of information technology and wide apply of the Internet, the pace of education reform is accelerated. The education of science and technology are getting towards network. The networked educational administration brings new ideas to education management. All the colleges and universities are striding forward to the academic affairs management of network process.

\section{The Framework and Characteristics of Educational Administration Platform}

The mainstream technology of modern educational administration management system software is divided into $\mathrm{C} / \mathrm{S}$ (Client/server) framework, B/S (Browser/server) framework and the $\mathrm{C} / \mathrm{S}$ and $\mathrm{B} / \mathrm{S}$ hybrid software architecture. The educational administration management platform of $\mathrm{C} / \mathrm{S}$ version is based on the client and the server structure. It is unequal and put forward for the realization of shared resources. The educational administration platform of $\mathrm{B} / \mathrm{S}$ version is based on the structure of browser. It is a three-layer structure and its background database using the Oracle and SQL Server.

The characteristics of $\mathrm{C} / \mathrm{S}$ structure are as follows. $\mathrm{C} / \mathrm{S}$ architecture is the frame structure of the educational administration system in the early development. It has strong ability of data operation and transaction processing. Its model is simple and easy to understand and accept by people. It has fast running transmission speed in the local area network (LAN) and good stable-performance. The most simple database application of $\mathrm{C} / \mathrm{S}$ architecture consists of two parts, namely the client 
application and database server program. They can be called the front desk and the background process. The machine running a database server program is called the application server. Once the server program is started, it is waiting for a response from the client requests; the client program runs on the user's own PC. The computer is called the client computer corresponding to the server computer. When you need to make any operation on data in the database, the client will automatically find the server program and send the request. The server program will respond to the request according to predetermined rules and send back the results. C/S structure defects mainly include the following:

a) The double $\mathrm{C} / \mathrm{S}$ structure is a single server and centers on the local network so that it is difficult to extend to wan or Internet;

b) The load to the server is too heavy to manage a large number of terminals. The performance of the system is easy to deteriorate;

c) The data security is not good. Because the client program can access directly to the database server and other programs on the terminal computer can also find a way to access the database server so that the database security is threatened.

The characteristics of B/S structure are as follows: The educational administration system on B/S architecture is rising in the early in the 21 st century. It mainly uses the World Wide Web browser technology and combines with a variety of scripting language of the browser. It realizes the power function by the universal browser which needs the complex special-purpose software originally. It is a new kind of software architecture. In the educational administration management software based on B/S system structure, system installation, modification and maintenance are solved on the server side. When users are in the use of the system, only a browser is needed to run all of the modules. It really achieves the function of "zero client".

$\mathrm{C} / \mathrm{S}$ and $\mathrm{B} / \mathrm{S}$ hybrid software architecture takes "one platform, two frameworks" as its principal theory, combines the B/S and C/S structure organically unifies in together for the user to quickly set up their own specific needs information work platform.

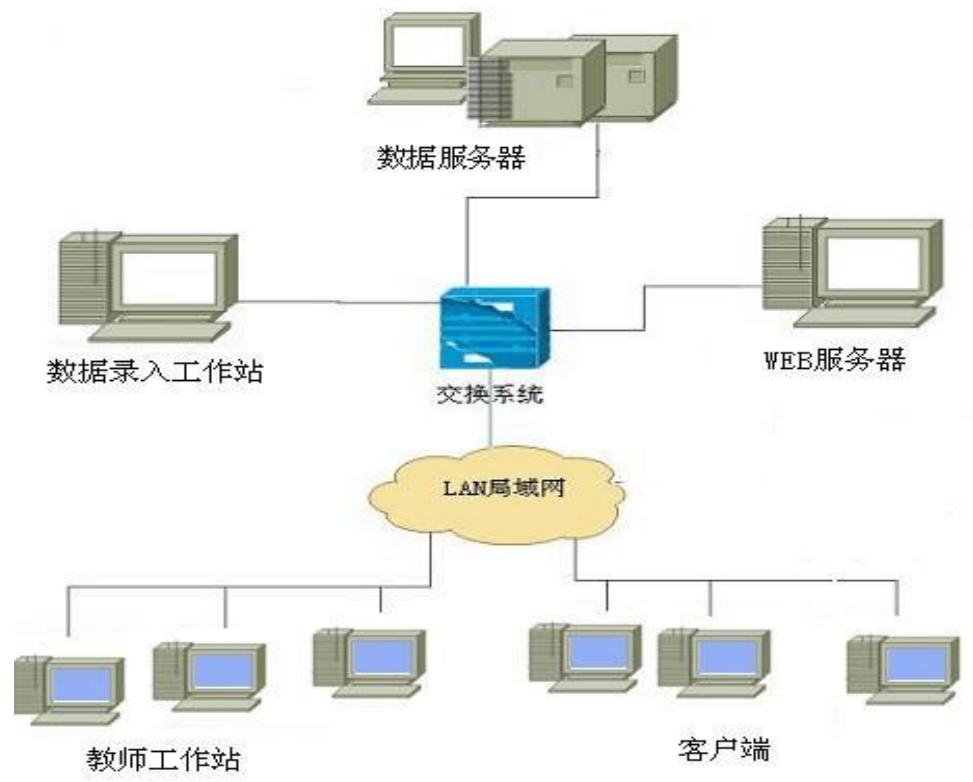

Figure 1. System network topology

\section{Functional Design of the Educational Administration Management Platform in Colleges and Universities}

With the expansion of the scale in colleges and universities, the development of higher education stage converts from quantity to quality promotion, as well as the transformation of "personalized training" model of institutions of higher learning. The modern educational administration 
management platform should reflect the education policy of "people-oriented" and meet the students' requirements such as choosing of a major and professional direction, curriculum elective mechanism, experiment booking requirements and implement functions including the talent training scheme in colleges and universities, student status, curriculum arrangement, platoon, course selection, network exam, textbooks, teaching quality monitoring and evaluation, practice teaching, teacher information, real-time release of teaching information management functions. Based on the experience of educational administration in our school in these years, modern educational administration should implement the following functions:

a) The management of the talent training scheme. The training scheme management is the foundation of the educational administration. The talent training scheme is the overall design and implementation scheme of colleges and universities, is the basic foundation of the arrangement of teaching content and the organization of teaching activities and related work. It is the first step of the talent training goal. Training scheme has a relative stability. The talent training scheme in traditional paper consult and use inconveniently so that teachers and students can't check in time. Through the educational administration system, teachers and students can query at any time, understand the professional and direction in a timely manner. Furthermore, through the brief introduction of the course, students can understand the learning content in advance.

b) The student status management. The student status management is the core of the educational administration management. It mainly includes registration information management, student achievement management and dynamic management. By students' only identification number in the information management, it realizes the management of each student's basic information, rewards and punishments and register management. The management of student performance is the basis of teacher's teaching effect and students' learning effect. It is also an important basis of the degree review. So the grade management needs to be safe and accurate. Modern educational administration management system should implement each student performance management function differently under the credit system. Student status change management implements the real change including students' drop out of school, study, turning professional, demotion, grade, school Trans ferment.

c) Course arrangement management. Course arrangement management is one of the most important link in teaching management work. It is also the most complicated and tedious work. Through setting teachers, classrooms, class time and curriculum schedule in the modern educational administration platform to realize automatic course arrangement. The system can determine the classroom capacity, classroom nature (multimedia, computer room), teachers' conflict and students' conflict, etc.

d) Examination arrangement management. Because of the expansion of college students, examination arrangement works have characters of more responsibility, hard task and tight time, the information and modernization of the examination work are more and more important. Through the educational administration system to set invigilation teachers, examination rooms, the test time, examination information and so on to realize automatic test plan management, the examination room arrangement and implement test plan more scientific and reasonable.

e) Course registration management. Independent course selection is the core of credit system and is the important means to realize student's personal cultivation. Modern educational administration system can accommodate ten thousand people to registrant courses at the same time. It can judge automatically whether the classes conflict. It can view the attention of the student's course schedule timely, follow tracks of hot courses and regulate and control the number of open courses. It can arrange resources according to the result of course after course and track the students' course selection bias.

f) Teacher management. The teacher is the leading role of teaching. Teacher's team is one of the most important resources in the teaching. Modern teacher management system takes teachers as objects and manages teachers in the basic information, teaching, movement, attendance, training and workload calculation, etc...

The establishment and perfection of the modern educational administration management system will make the educational administration department to get rid of the "transactional" and 
"experience" old management framework. At the meanwhile, it requires the department of educational administration management itself to be standardization and modernization in management manner and the work mentality. It has great significance to ensure high efficiency and high quality in the educational administration management.

\section{References}

[1] Xu Hui. Research on the construction and practice of information construction and practice of educational administration management in Colleges and universities [J]. Anhui Literature (second half), 2008 (09) (in the second half).

[2] Shao Changkai. MIS model and b/s model in the development of c/s model of comparative analysis [J]. Fujian computer. 2007 (10), ()

[3] Wang Honglin, Douliang, Zheng Youfei, sun Caiyun. Based on B / S structure of the laboratory information management system design and implementation [J]. Experimental technology and management, 2007 (2008)

[4] He Zhan, Liu Fei. College of educational administration information system based on C/S and B/S mode [J]. Journal of Wuhan University of Science and Engineering. 2006 (11)

[5] Wang Yulian, Li Jihong. Application of the comprehensive educational administration system in the educational administration management [J]. Computer engineering and design. 2004 (10)

[6] Cao Liyan, Zheng Yichang. Of course selection system in Colleges and universities in China and countermeasures [J]. Inner Mongolia Normal University Journal (EDUCATION SCIENCE EDITION), 2004 (2009)

[7] Chen Li, Wang Yindi, Tian Bing. [J]. teaching management system of higher education of science based on campus network. 2003 (03)

[8] Liu Deshan, Yang Chunzhi. College of educational administration management information system based on $\mathrm{C} / \mathrm{S}$ and $\mathrm{B} / \mathrm{S}$ mixed structure $[\mathrm{J}]$. Journal of Liaoning Normal University (NATURAL SCIENCE EDITION). 2002 (04)

[9] Li Shihong. Discussion on the construction and development of the academic affairs management in the wave of information technology [J]. Journal of Changchun University of Science and Technology (SOCIAL SCIENCE EDITION). 2002 (04)

[10] Xu Xiufen, Lu Hualin. Thinking of educational modernization management and technical economy analysis of [J]. Industry (03) 2002. 